ZONGZHI LI, Ph.D. ${ }^{1}$

(Corresponding Author)

E-mail: lizz@iit.edu

HOANG DAO, Ph.D. ${ }^{1}$

E-mail: hdao@hawk.iit.edu

HARSHINGAR PATEL, Ph.D. ${ }^{1}$

E-mail: hpatel93@hawk.iit.edu

YI LIU, PH.D. ${ }^{2}$

E-mail: liuy87@hotmail.com

BEI ZHOU, Ph.D. ${ }^{3}$

E-mail: bzhou2007@gmail.com

${ }^{1}$ Department of Civil, Architectural and Environmental

Engineering, Illinois Institute of Technology

3201 South Dearborn Street, Chicago, IL 60616

2 School of Navigation, Wuhan University of Technology

1178 Hepindadao, Wuchang, Wuhan, Hubei, 430063,

China

${ }^{3}$ College of Highways, Chang'an University

South Middle Section, $2^{\text {nd }}$ Ring Road, Xi'an, Shaanxi,

710064, China
Safety and Security in Traffic Original Scientific Paper Submitted: 5 Jan. 2016 Accepted: 16 Nov. 2016

\title{
INCORPORATING TRAFFIC CONTROL AND SAFETY HARDWARE PERFORMANCE FUNCTIONS INTO RISK-BASED HIGHWAY SAFETY ANALYSIS
}

\begin{abstract}
Traffic control and safety hardware such as traffic signs, lighting, signals, pavement markings, guardrails, barriers, and crash cushions form an important and inseparable part of highway infrastructure affecting safety performance. Significant progress has been made in recent decades to develop safety performance functions and crash modification factors for site-specific crash predictions. However, the existing models and methods lack rigorous treatments of safety impacts of time-deteriorating conditions of traffic control and safety hardware. This study introduces a refined method for computing the Safety Index (SI) as a means of crash predictions for a highway segment that incorporates traffic control and safety hardware performance functions into the analysis. The proposed method is applied in a computation experiment using five-year data on nearly two hundred rural and urban highway segments. The root-mean square error (RMSE), Chi-square, Spearman's rank correlation, and Mann-Whitney $U$ tests are employed for validation.
\end{abstract}

\section{KEY WORDS}

traffic control; safety hardware; safety performance function; highway safety; risk analysis;

\section{INTRODUCTION}

Highway analysis and management have evolved over the years to become an all-encompassing effort with safety of the users included as an over-arching goal. Over the past few decades, many analytical methods, models, and tools have been developed and refined to realistically estimate vehicle crashes on a highway segment. In addition, they quantify the expected benefits of safety improvement projects, and prioritize the economically feasible projects under budget constraints to ensure achieving the maximized safety benefits to users on the highway system. The various categories of traffic control and safety hardware, such as traffic signs, lighting, signals, pavement markings, guardrails, barriers, and crash cushions require holistic management with the highway facilities, vehicles, drivers, and the environment to collectively reach effective safety performance. The required analytical methods for traffic control and safety hardware are an important and non-separable part for holistic and efficient safety analysis and management.

The interaction of factors relating to highway facilities, vehicles, drivers, and environment, contribute to the occurrence of a vehicle crash on a highway segment. Over the past few decades, researchers have studied the categories of geometric design, consistency of design standards, pavement conditions, and roadside features for detailed analysis of safety issues attributable to highway segments [1, 2, 3, 4, 5]. Meanwhile, the condition of the traffic control and safety hardware has a significant impact on the safety of the users. In fact, the service lives of major highway facilities contributing to the safety performance 
of the system are significantly longer than the useful service lives of different categories of traffic control and safety hardware. This leads to more frequent replacement of traffic control and safety hardware, adding to relatively high maintenance costs of the safety hardware system. Researchers have attempted to incorporate the concept of performance-based analysis relying on the condition of facility preservation and impacts of changes in the facility condition on the performance for safety analysis and project evaluation. Madanu et al. [6] developed a methodology incorporating the life-cycle cost analysis for refined estimation of impacts of the traffic control and safety hardware on crash predictions, to address the limitations of the existing traditional methods for safety impacts assess ment of highway safety hardware improvements. The risk-based methods for safety analysis employ the computation of the safety index (SI) by combining the traffic exposure, crash frequency, and crash severity factors for estimating the crash frequency associated with a highway segment [2, 5, 7, 8, 9]. However, the available methods have a limitation with regard to estimating the changes in the crash frequency and the severity level after implementing traffic control and safety hardware improvement projects during the course of highway facility service life-cycle. The estimated changes in the observed crash frequency and severity post-implementation of safety improvement projects are computed by considering the conditions of the traffic control and safety hardware as average constant observed values, which in reality might not be applicable to site-specific conditions for a long period of time [8, 9]. Alternatively, Madanu et al. [6] used the pre-and post-implementation percentage changes in the observed crash frequency by severity level for comparable sites for a safety improvement project, but did not capture the variability of such changes that are collectively affected by multiple crash contributing factors over time. As a practical matter, the percentage changes are dependent on the time of the observed data with respect to the useful service life of the traffic control and safety hardware. The varying service lives of different highway facility components and the time-varying nature of changes in the traffic control and safety hardware conditions make estimating the comparative rate of changes for any given service time period difficult for the purpose of safety-related project assessment. In order to address this limitation, it is necessary to use the performance functions corresponding to different categories of traffic control and safety hardware, which are a function of time for the analysis.

In this context, research was conducted to develop performance functions for traffic signs, traffic signals, and pavement markings. For instance, Black et al. [10] carried out performance modelling of traffic signs, and observed that the retroreflectivity of traffic signs decreases over time except in case of red high intensity sheeting where retroreflectivity value decreases in the first five years and starts to increase owing to the fade of the red ink to cause an increase in red high intensity retroreflectivity value. Wolshon [11] compared high intensity grade sheeting and engineering grade sheeting, based on the impacts of exposure of the traffic signs to sun over the service life depending on the sheeting grade, conditions, and direction of installation of the traffic sign. The study reported that the high intensity grade sheeting performed better than the engineering grade sheeting. Pertaining to lights, nowadays, Light Emitting Diode (LED) lights are popular owing to the longer life expectancy, low maintenance and energy requirements, and an overall cheaper life-cycle cost. Long et al. [12] introduced a method to determine the lifetime of LED-based traffic lights by considering measurements of lumen maintenance and temperature, evaluated the service life of LED-based traffic signals, and classified them by manufacturer, function, and colour using light intensity as the measurement of LED degradation. For pavement marking performance modelling, Lindly et al. [13] used the concept of Cumulative Traffic Passages (CTP) determined by using daily traffic, number of lanes, and the age of pavement markings, based on which statistical models were developed to establish a relationship between retroreflectivity of pavement markings and CTP by means of linear and exponential regression analyses. Bahar et al. [14] also developed models for pavement marking retroreflectivity deterioration over time by material used, traffic condition, and weather condition. Avelar and Paul [15] analyzed the relationship between pavement marking retroreflectivity and night-time safety and found that sites with low centreline retroreflectivity (compared with edge line retroreflectivity of the same road) were associated with more crashes. Guo et al. [16] indicated that parallelogram-shaped pavement markings significantly reduced vehicle speeds and speed violations in the vicinity of pedestrian crosswalks.

This study introduces a refined method based on the risk-based safety analysis method developed by Madanu et al. [6], which incorporates traffic control and safety hardware performance functions into the analytical process. The contribution of this research is in terms of the refinements, specifically utilizing the time-varying safety hardware performance functions to compute the Safety Index (SI) which correlates the traffic control and safety hardware condition prior to safety improvements with changes in the hardware condition after improvements. Here, changes in hardware condition are treated as a variable that is estimated by the hardware performance functions. The refined method is based on the existing risk-based safety analysis methods, benefitting from their established framework, but it goes one step further by 
incorporating performance-based considerations for the traffic control and safety hardware.

\section{PROPOSED METHOD}

The proposed method in the present study is a riskbased safety analysis approach for computation of the SI value based on conditions of traffic control and safety hardware within a highway segment, and their effect on the associated vehicle crash risks on the highway segment. The available methods for computing the SI values depend on the expert opinion and the average extent of deterioration in the conditions of traffic control and safety hardware before and after safety improvements to quantify the impacts of traffic control and safety hardware on associated vehicle crash risks. The present study aims to overcome this specific limitation by refining the existing risk-based methods to utilize performance functions of traffic control and safety hardware over time to model its performance trends.

The methodological refinements proposed in this study consider various categories of traffic control and safety hardware such as traffic signs, lighting, signals, pavement markings, barriers, and guardrails, along with geometric design, consistency of design standards, and pavement conditions. The performance measures used for traffic signs, street lighting, traffic signals, pavement markings and guardrails are retroreflectivity, lumen maintenance, light intensity, retroreflectivity, and shrinkage strain, respectively. The study is made on the assumption that all categories of traffic control and safety hardware are installed new at the beginning of the study period, and will deteriorate based on their individual performance functions over time, without any repairs and will be replaced at the end of their useful service life. The following sections details the process and parameters for computing the $\mathrm{SI}$ value as a means of crash predictions for a highway segment.

\subsection{Methodology overview}

A vehicle crash on a highway segment is attributable to a number of factors associated with highway facilities, vehicles, drivers, and weather conditions. The crash contributing factors for the purpose of crash estimation on a segment include geometric design, traffic operation characteristics, pavement conditions, roadside features, and traffic control and safety hardware conditions. The SI value associated with a highway segment is the quantification of the associated vehicle crash risks with which the conditions of the safety and traffic hardware on the segment contribute to crash occurrences.

\begin{tabular}{|l|l|}
\hline Step 1: & $\begin{array}{l}\text { Categorize the highway segment by land area and } \\
\text { functional class and crashes by type and severity }\end{array}$ \\
\hline Step 2: & $\begin{array}{l}\text { Compute the crash risk factors attributable to: I) geo- } \\
\text { metric design, II) traffic operations, III) traffic control } \\
\text { and safety hardware conditions, and IV) roadside } \\
\text { features }\end{array}$ \\
\hline Step 3: & $\begin{array}{l}\text { Compute the traffic exposure, crash frequency, and } \\
\text { crash severity factors based on historical data with } \\
\text { percentage changes in crash frequency and severity } \\
\text { as a function of traffic control and safety hardware } \\
\text { performance functions }\end{array}$ \\
\hline Step 4: & $\begin{array}{l}\text { Compute the safety index (SI) by crash severity level } \\
\text { and type affected by traffic control and safety hard- } \\
\text { ware conditions }\end{array}$ \\
\hline Step 5: & $\begin{array}{l}\text { Validate the SI values using analytical procedures and } \\
\text { statistical tests }\end{array}$ \\
\hline
\end{tabular}

Figure 1 - Proposed methodology for computing the SI value of a highway segment

Figure 1 illustrates the main computational steps involved in the proposed analytical process. The first step in the process of SI computation is categorization of the highway system based on land area (rural and urban) and highway functional class (Interstate, multi-lane, and two-lane). Vehicle crashes are categorized as fatal, injury and property damage only (PDO) crashes per highway segment per year. Next, the crash risk factors attributable to each category of geometric design, traffic operation characteristics, pavement conditions, roadside features, and traffic control and hardware conditions are computed. The various categories of traffic control and safety hardware utilized for the purpose of SI computation are traffic signs, lighting, signals, and pavement markings, while barriers and guardrails are considered as the roadside features, along with the geometric design, consistency of design standards, and pavement conditions amongst other factors. One or more hardware items, in each category of traffic control and safety hardware may be involved for SI computation. The third step is to calculate the traffic exposure factor (TEF), crash frequency factor (CFF), and crash severity factor (CSF) based on historical data. Next, the probability of each type of crashes occurring and the TEF, CFF and CSF are used to compute the SI value. The contribution of the proposed methodological refinements forms the fourth step, which is the computation of CFF and CSF and the respective percentage changes, estimated as functions of the performance of individual traffic control and safety hardware items over time. This implies that the crash frequency associated with each traffic control and safety hardware item will vary with 
time. Moreover, it is assumed that the traffic control and safety hardware item is replaced multiple times over the useful service life of the highway segment, as the service life of traffic control and safety hardware is significantly shorter as compared to that of a highway segment. In order to compute the SI for the crash severity level, the logarithmic possibility-probability transformation approach proposed by Klir [17] is used to convert the crash possibility distribution to crash probability distribution. The method uses historical data to establish the possibility distribution of the identified crash type, which in turn is utilized to compute the generalized Hartley measure and estimate the probability distribution. Finally, in order to validate the SI value established by the proposed risk-based method, its results are compared with the crash frequency calculated using the Empirical Bayesian (EB) before-after analysis method, in conjunction with the field observed crash records [18].

\subsection{Methodology computation}

Calculation of the SI value for a highway segment. This section elaborates the proposed method for computing the SI value introduced in the above section. SI is a combination of the Traffic Exposure Factor (TEF), Crash Frequency Factor (CFF), and Crash Severity Factor (CSF); where TEF is a function of traffic volume on the highway segment; CFF is an estimated factor based on the crash risk factors computed using geometric design, traffic operations characteristics, pavement conditions, and traffic control and safety hardware conditions; and CSF is estimated using crash risk factors associated with roadside features. The SI value of a highway segment for categories of fatal, injury and PDO crashes can be calculated as [7, 9]:

$S I_{s}=T E F_{s} \cdot \sum_{r=1}^{R}\left[P(r) \cdot C F F_{r s} \cdot C S F_{r s}\right]$ where:

$\mathrm{SI}_{\mathrm{s}} \quad$-safety index of a highway segment for crash severity level s,

$T E F_{s}$-overall TEF for crash severity level s,

$P(r)$ - probability of occurring type $r$ crashes,

CFF $_{r s}$-overall crash frequency factor measuring the risk of increasing the crash frequency,

$\mathrm{CSF}_{r \mathrm{~s}}$ - overall crash severity factor measuring the risk of increasing the crash severity.

Determination of traffic exposure factor. TEF associated with a highway segment quantifies the safety hazards that the users are exposed to, which can be computed by the formulation given below $[8,9]$ :

$T E F_{S}=L \cdot\left(365 \cdot A A D T^{a}\right)$

where:

L $\quad$-length of the highway segment under consideration, in $\mathrm{km}$,

$A A D T$-annual average daily traffic, in vehicles per day,

a -exponent of AADT in the safety performance function with $a<1$ to consider non-linearity between crashes and traffic volume or is set to 1 if safety performance function is not available.

Traffic control and safety hardware performance functions for estimating changes in crash frequency and severity level. The performance functions and rates of deterioration for individual traffic control and safety hardware items associated with a highway segment are modelled and estimated. For the purpose of the current study, performance functions calibrated for traffic signs, signals, and pavement markings in the existing literature are adopted. Table 1 presents details of traffic sign retroreflectivity performance functions [10].

With regards to traffic signals, the available literature indicates that because of its advantages of energy saving, environment, and long service life-cycle, the use of LED lamps for traffic signal heads is popular.

Table 1 - Traffic sign retroreflectivity performance functions

\begin{tabular}{|c|c|c|}
\hline Sign Type & Grade & Performance functions \\
\hline Red & \multirow{3}{*}{$\begin{array}{l}\text { Engineering } \\
\text { High-intensity }\end{array}$} & $S I A=21.466-1.269$ (Age)-0.0004(DegDays) $+0.124($ Precip $)+0.0003($ Ele $)$ \\
\hline Age $\leq 5$ & & $S I A=38.97-3.574($ Age $)+0.0001$ (DegDays)+0.24(Precip)-0.001(Ele) \\
\hline Age $>5$ & & $S I A=19.765+2.496($ Age $)-0.00003($ DegDays $)+0.067($ Precip $)+0.0001($ Ele $)$ \\
\hline \multirow{2}{*}{ Yellow } & \multirow{2}{*}{$\begin{array}{l}\text { Engineering } \\
\text { High-intensity }\end{array}$} & $S I A=78.794-3.906$ (Age)-0.002(DegDays)+0.115(Precip)+0.002(Ele) \\
\hline & & $S I A=247.85-4.578($ Age $)-0.001$ (DegDays) $+0.174($ Precip $)+0.002($ Ele $)$ \\
\hline \multirow{2}{*}{ White } & \multirow{2}{*}{$\begin{array}{l}\text { Engineering } \\
\text { High-intensity }\end{array}$} & $S I A=103.085-5.451($ Age $)+0.002$ (DegDays)+0.178(Precip)+0.002(Ele) \\
\hline & & $S I A=304.089-4.851$ (Age) $+0.002($ DegDays $)+0.06($ Precip $)+0.001($ Ele $)$ \\
\hline \multirow{2}{*}{ Green } & \multirow{2}{*}{$\begin{array}{l}\text { Engineering } \\
\text { High-intensity }\end{array}$} & $S I A=15.990-0.637($ Age $)+0.0003($ DegDays $)-0.036($ Precip $)+0.0001($ Ele $)$ \\
\hline & & $S I A=53.386-1.345$ (Age)-0.002(DegDays)+0.337(Precip)+0.003(Ele) \\
\hline
\end{tabular}

Note: SIA - predictive traffic sign retroreflectivity, candela/lux $/ \mathrm{m}^{2}$, Age - age category of sign sheeting, years, DegDays - annual heating degree-days, Precip - annual precipitation, inches, Ele - average ground elevation, feet. 
Table 2 - LED traffic signal head performance functions

\begin{tabular}{||c|c|c|c|c||}
\hline \multicolumn{2}{|c|}{ Type (Manufacturer) } & Performance Functions & Threshold & Service Life [years] \\
\cline { 2 - 5 } Circular Green & $(\mathrm{GE})$ & $\mathrm{Y}=-28.139 X+386.6$ & 257 & 5 \\
\cline { 2 - 5 } & $(\mathrm{DIAL})$ & $\mathrm{Y}=-32.415 X+531.07$ & 257 & 8 \\
\hline \multirow{3}{*}{ Arrow Green } & $(\mathrm{GE})$ & $\mathrm{Y}=-9.8846 X+116.46$ & 41 & 7 \\
\cline { 2 - 5 } & $(\mathrm{DIAL})$ & $\mathrm{Y}=-12.681 X+154.61$ & 41 & 9 \\
\hline \multirow{2}{*}{ Circular Yellow } & $(\mathrm{DIAL})$ & $\mathrm{Y}=-8.185 X+530.28$ & 491 & 6 \\
\hline \multirow{2}{*}{ Circular Red } & $(\mathrm{GE})$ & $\mathrm{Y}=-33.366 X+274.37$ & 79 & 6 \\
\cline { 2 - 5 } & $(\mathrm{DIAL})$ & $\mathrm{Y}=-5.9974 X+115.56$ & 79 & 9 \\
\hline \hline
\end{tabular}

Note: Y- light intensity, $X$ - age, Years - made up to be integer.

The light output in lumen of LED signal heads can be formulated as [12]:

$L_{L E D}=L_{0} \cdot e^{-\alpha\left(T_{j}\right) t}$

where:

$\alpha$ - light output deterioration rate, $\alpha$ is set as 10 , $20,30,40$ or 50 percent,

$t$-operation time, in hours,

$L_{0} \quad$-initial light output,

$T_{j} \quad$-temperature at time $\mathrm{t}$ is related to the initial $\left(T_{j}^{0}\right)$; the final $\left(T_{j}^{f}\right)$ and the increase rate $(m, n)$ of temperature by logarithmic, linear, and exponential functional forms.

The present study utilizes performance functions of LED traffic signal heads developed by Long et al. [12] for estimating the rates of degradation of performance, as detailed in Table 2, where all the lights are categorized by manufacturer, life, colour, and directional view.

For the purpose of modelling the performance of pavement markings, researchers introduced cumulative traffic passages (CTP) based on evaluation of flat thermoplastic markings (FTM) and profiled pavement markings (PPM) that can be computed by Equation 4 [13]:

$$
\begin{aligned}
\text { CTP }= & {[\text { AADT } \text { (millions }) \cdot \text { Age of Marking (days) }] / } \\
& /\left[10^{6} \cdot \text { Number of Lanes }\right]
\end{aligned}
$$

Based on the computed value of CTP as detailed above, the relationship between the pavement marking retroreflectivity $(R)$ and CTP has been developed by the Alabama University Transportation Center (AUTC) presented as linear and exponential performance functions as detailed in Table 3 [13]:.

Computation of crash frequency factor. The CFF for a highway segment indicates the associated risk of increase in the observed crash occurrences. It is computed as the product of CFF by crash type $r$ and severity category s, for each general crash risk factor i associated with geometric design, traffic operation characteristics, pavement conditions, roadside features, and traffic control and safety hardware conditions. Crash frequency factor pertinent to risk factor, crash type, and crash severity is computed by combining the weights $\left(W_{i j}\right)$, relative increase in percentage of crash frequency as a function of time $\left(\Delta C F_{r s i j}\right)$, and crash frequency proportion factor $\left(P_{r s i j}\right)$ for each of its constituent crash risk factors $\mathrm{j}$ for each identified general crash risk factor i $[8,9]$.

$$
C F F_{r s}=C F F_{r s 1} \cdot C F F_{r s 2} \cdot \ldots \cdot C F F_{r s i} \cdot C F F_{r s l}
$$

$$
C F F_{r s i}=1+\sum_{j=1}^{J} W_{i j} \cdot \Delta C F_{r s i j} \cdot P_{r s i j}
$$

where:

$\mathrm{CFF}_{r s}$-overall crash frequency factor for a highway segment,

$\mathrm{CFF}_{\text {rsi }}$-crash frequency factor concerning general crash risk factor $i$ for a highway segment,

\begin{tabular}{|c|c|c|}
\hline Pavement Markings Types & Model Forms & Performance Functions \\
\hline \multirow{2}{*}{ Flat thermoplastic (FTM) } & Linear (L) & $R_{F T M}^{L}=310-31.1 \cdot C T P$ \\
\hline & Exponential (E) & $R_{F T M}^{E}=329 \cdot e^{-0.16 \cdot C T P}$ \\
\hline \multirow{2}{*}{ Profiled (PPM) } & Linear (L) & $R_{P P M}^{L}=239-28.9 \cdot C T P$ \\
\hline & Exponential (E) & $R_{P P M}^{E}=244 \cdot e^{-0.16 \cdot C T P}$ \\
\hline
\end{tabular}

$W_{i j} \quad$-weighting of detailed crash risk factor $j$ under general crash risk factor $i$,

Table 3 - Pavement marking retroreflectivity performance functions 
$\Delta C F_{r s i j}$-relative increase in crash frequency before and after hardware improvements,

$P_{\text {rsij }}$-crash frequency proportion factor as the proportion of segment crashes affected by detailed crash risk factor $j$ under general crash risk factor $i$,

$r$-crash type, including head-on, side swipe, $f$ ixed object, run-off-road,

$s \quad$-crash severity category, including fatal, injury and property damage only (PDO).

In order to consider the length of a highway segment and the associated safety issue it is exposed to, a weighting factor $W_{i j}$ is determined, for the safety issues related to geometric design, pavement conditions, and traffic control and safety hardware conditions, which are estimated based on historical data. $W_{i j}$ is a ratio between the crash risk factor for an affected length of segment and the total length of the highway segment under consideration. The crash frequency proportion factor $P_{\text {rsij, }}$ which is the ratio between the cumulative number of crashes affected by a crash risk factor. The total number of crashes on the highway segment affected by the detailed crash risk factor can be determined based on historical data as well and it represents the proportion of segment crashes affected by detailed crash risk factor $j$ under general crash risk factor $i$ for crash type $r$ and severity category s.

As shown in Equation 6, the relative increase in crash frequency $\Delta C F_{r s i j}$ for each detailed crash risk factor $j$ under general crash risk factor $i$ with respect to crash type $r$ and severity category $s$ is estimated as relative increase in crashes estimated by the applicable segment related accident modification factor [8, 9]. The current study introduces the concept of this relative increase in crash frequency $\Delta C F_{r s i j}$ as a function of time and computes it based on traffic control and safety hardware performance such that the existing method of safety impacts analysis is refined to reflect the true impact of time on the deterioration of the highway hardware and quantification of the impacts in terms of changes in crashes in the system. It is assumed that, over time, when traffic control and safety hardware conditions deteriorate, crash frequency will increase. In order to evaluate the relation between traffic control and safety hardware performance and crash frequencies, the relative increase in crash frequency factor is formulated as follows and used in Equation 6 for the crash frequency factor calculation:

$$
\Delta C F_{r s i j}=\left[\left[\frac{f\left(C F_{r s i j, 0}\right)-f\left(C F_{r s i j, t}\right)}{f\left(C F_{r s i j, 0}\right)-f\left(C F_{r s i j, T}\right)}\right] \cdot 100 \%\right]
$$

where:

$\Delta C F_{r s i j}$ - percentage increase in crash frequency,

$\mathrm{CF}_{r s i j, 0}$-initial value of the CF contributing factor when the hardware is first installed,

$C F_{r s i j, T}$-terminal value of the CF contributing factor when the hardware needs to be replaced,
$C F_{r s i j, t}$-value of the CF contributing factor at time $t$.

This formulation captures the performance of traffic control and safety hardware over time, and differentiates the effect of calculating a similar value of $\Delta C F_{r s i j}$ for two different sets of performance values over a performance curve.

Estimation of crash severity factor. The crash severity factor $\mathrm{CSF}_{r s}$ attributable to roadside features and operating speed of the vehicle involved in the crash is computed as the product of crash severity factors by crash type $r$ and by crash severity level $s$ for general risk factors $i$, by combining the weights of crash risk factors, relative change in the crash severity, and crash proportion factor for all constituent crash risk factors $j[8,9]$.

$C S F_{r S i} R S H=1+\sum_{j=1}^{j} W_{i j_{-} R S H} \cdot \Delta C S_{r s i j} \cdot P_{r s i j \_R S H}$

where:

$W_{i j \_R S H}$-weighting of detailed crash risk factor $j$ under roadside feature crash risk factor $\mathrm{i}$,

$\Delta C S_{r s i j}$-relative increase in crash severity before and after hardware improvements,

$P_{\text {rsij_RSH }}$-crash severity proportion factor as the proportion of crashes affected by detailed crash risk factor $j$ under roadside feature-related crash risk factor $i$.

For each type of crashes affected by roadside features, the injury, fatal, and PDO crash severity factors are formulated in the following equations:

$$
\begin{aligned}
& C S F_{r, l, i_{\_} R S H}= 1+\sum_{j=1}^{j} W_{i, j_{\_} R S H} \cdot \Delta C S_{r s i j} \cdot P_{r, l, i, j_{-} R S H} \\
& C S F_{r, F, i_{-} R S H}= 1+\sum_{j=1}^{j} W_{i, j_{-} R S H} \cdot \\
& \cdot\left[\Delta C S_{r S i j}\left(1+\Delta S_{r, F, i, j_{-} R S H}\right)\right] \cdot P_{r, l, i, j_{-} R S H} \\
& C S F_{r, P, i_{-} R S H}= 1+\sum_{j=1}^{j} W_{i, j_{-} R S H} \cdot \\
& \cdot\left[\Delta C S_{r S i j}\left(1+\Delta S_{r, P, i, j_{-} R S H}\right)\right] \cdot P_{r, l, i, j_{-} R S H}
\end{aligned}
$$

where:

$\mathrm{CSF}_{r, l, i_{1} R S H}$-injury crash severity factor,

$C S F_{r, F, i_{1} R S H}$-fatal crash severity factor,

$\mathrm{CSF}_{r, P, I_{-} R S H}$-PDO crash severity factor,

$W_{i, j \_R S H}$-weighting of roadside features related to crash risk factor,

$\Delta \mathrm{CS}_{r s i j} \quad-$ relative increase in crash severity before and after hardware improvements,

$\Delta S_{r, F, i, j \_R S H}$-relative increase in fatal crash risk over injury crash risk,

$\Delta S_{r, P, i, j \_R S H}$-relative increase in PDO crash risk over injury crash risk,

$P_{r, l, i, j \_R S H} \quad$ - crash frequency proportion factor as the proportion of injury crashes. 
The injury crash weighting factor $W_{r, l, i, j}$ is the ratio between the roadside safety issue item affected length and the total length of the highway segment, for each roadside safety issue item $j$ under roadside safety issue type $i$. It is computed in the same manner as the crash frequency weighting factor. The relative increase in fatal crash risk $\Delta S_{r, F, i, j} R S H$ can be determined as the percentage change in fatal and injury crash rates over injury crash rate using historical crash data. Similarly, the relative increase in PDO crash risk $\Delta S_{r, P, i, j \_} R S H$ over the injury crash risk can be estimated as the percentage change in the injury and PDO crash rates.

The following formulation considered in Equations 9-11 for the purpose of computing the Crash Severity Factors quantifies the relative increase in crash severity factor $\Delta C S_{r s i j}$, by utilizing safety performance functions for predicting fatal, injury, and PDO crashes adjusted to account for traffic control and safety hardware conditions that deteriorate over time as follows:

$\Delta C S_{r s i j}=\left[\left[\frac{f\left(C S_{r s i j, 0}\right)-f\left(C S_{r s i j, t}\right)}{f\left(C S_{r s i j, 0}\right)-f\left(C S_{r s i j, T}\right)}\right] \cdot 100 \%\right]$

where:

$\Delta C S_{r s i j}$ - percentage change in the Crash Severity Factor for all types of crashes,

$\mathrm{CS}_{r s i j, 0}$-initial value of the CS contributing factor when the hardware is first installed,

$\mathrm{CS}_{r s i j, T}$-terminal value of the CS contributing factor when the hardware needs to be replaced,

$C_{\text {rsij, } t}$-value of the CS contributing factor at time $t$.

The importance of this computation of performance of the traffic control and safety hardware as a function of time is evident. As the condition of the hardware deteriorates over time, the impact of the assumed value of the hardware performance on the associated vehicular crash risk also increases. This is the refinement achieved by this study which considers the performance of all traffic control and safety hardware as a function of time, and not an average value.

Probability in the occurrences of different types of crashes. The historical data provide the highway seg ment-related vehicle crashes and their categorization by type and severity. However, in order to predict the vehicle crashes on the segment in the future year, it is imperative to ascertain the probability distribution of these crashes by type and severity for the group of highway segments within a highway system by land area and functional class. A logarithmic transformation method introduced by Klir [17] can be followed to convert the crash possibility distribution to the crash probability distribution, by using identification of the crash types from historical data and then determining its possibility distribution to compute the generalized Hartley measure to establish the probability distribution.

\subsection{Methodology validation}

The necessity for refining the existing methods for predicting vehicle crashes expected on a highway segment for the purpose of SI computation is to accurately assess crash impacts of detailed crash risk factors relevant to geometric design, traffic volumes and operations, pavement conditions, roadside features, and traffic control and safety hardware conditions. The proposed method refines the resultant SI values. However, the results require validation. For this purpose, $\mathrm{SI}$ values are compared with the Empirical Bayesian (EB) adjusted crash estimates that eliminate the regression-to-mean bias by taking the weighed sum of observed and predicted crash frequencies [18, 19]. The EB estimate is computed as:

$$
E B_{i}=w \cdot P_{i}+(1-w) \cdot O_{i}
$$

$w=\frac{\frac{1}{k}}{\frac{1}{k}+P_{i}}$

where:

$E B_{i}$-EB crash estimate for highway segment $i$,

$P_{i} \quad$ - crash frequency predicted by a safety performance function for highway segment $i$,

$\mathrm{O}_{i}$-observed number of crashes during the specified period for highway segment $i$,

w -relative weight between the predicted and observed crash frequencies,

$k \quad$-overdispersion factor of the negative binomial safety performance function.

Further, the computed SI values and EB crash frequency estimates are correlated by means of a linear regression model with the adjusted $\mathrm{R}^{2}$ as an indicator for the correlation significance. In order to compare the consistency of SI and EB estimates, Root-mean-square error (RMSE) and Geoffrey E. Havers (GEH) values are computed. Additionally, Chi-square, Spearman's rank correlation, and Mann-Whitney $U$ tests are also conducted $[20,21]$.

\section{METHOD APPLICATION}

\subsection{Data collection and SI computation}

The computational experiment to validate the proposed method uses data on highway geometric design, conditions of traffic control and safety hardware including pavement markings and traffic signs, and crash data from Ozaukee County, Wisconsin, USA over the time from 2002-2006. The county covers a total area of 1,116 square miles including 232 square miles of land and 884 square miles of water. Table 4 presents the data summary. 
Z. Li et al.: Incorporating Traffic Control and Safety Hardware Performance Functions into Risk-based Highway Safety Analysis

Table 4 - Summary data of the computational study

\begin{tabular}{|c|c|c|c|c|c|c|c|c|}
\hline \multirow{2}{*}{\multicolumn{2}{|c|}{\begin{tabular}{|l} 
Data Item \\
\end{tabular}}} & \multicolumn{4}{|c|}{ Urban Area } & \multicolumn{3}{|c|}{ Rural Area } \\
\hline & & \multirow{2}{*}{$\begin{array}{c}\text { Interstate } \\
30\end{array}$} & \multirow{2}{*}{$\begin{array}{c}\text { Multilane } \\
\text { Divided }\end{array}$} & \multirow{2}{*}{$\begin{array}{c}\text { Multilane } \\
\text { Undivided } \\
3\end{array}$} & \multirow{2}{*}{$\begin{array}{c}\text { Two-lane } \\
44\end{array}$} & \multirow{2}{*}{$\begin{array}{c}\text { Interstate } \\
22\end{array}$} & \multirow{2}{*}{$\begin{array}{c}\text { Multilane } \\
\text { Divided }\end{array}$} & \multirow{2}{*}{$\begin{array}{c}\text { Two-lane } \\
7\end{array}$} \\
\hline Segments & (No.) & & & & & & & \\
\hline Lengths & $(\mathrm{km})$ & 51.21 & 43.61 & 2.75 & 33.32 & 37.45 & 27.95 & 7.91 \\
\hline \multirow{5}{*}{$\begin{array}{c}\text { AADT } \\
\text { [veh/day] }\end{array}$} & 2002 & 48,174 & 12,798 & 13,299 & 13,460 & 26,423 & 10,782 & 11,127 \\
\hline & 2003 & 48,826 & 12,918 & 13,431 & 13,605 & 26,687 & 10,874 & 11,258 \\
\hline & 2004 & 49,488 & 13,039 & 13,564 & 13,752 & 26,954 & 10,967 & 11,390 \\
\hline & 2005 & 50,158 & 13,162 & 13,699 & 13,900 & 27,225 & 11,061 & 11,524 \\
\hline & 2006 & 50,838 & 13,285 & 13,834 & 14,050 & 27,498 & 11,156 & 11,660 \\
\hline \multirow{5}{*}{$\begin{array}{c}\text { Fatal } \\
\text { [Crashes/year] }\end{array}$} & 2002 & 8 & 10 & 2 & 6 & 4 & 4 & 1 \\
\hline & 2003 & 7 & 8 & 0 & 7 & 1 & 1 & 2 \\
\hline & 2004 & 9 & 5 & 1 & 6 & 4 & 5 & 1 \\
\hline & 2005 & 5 & 8 & 1 & 6 & 2 & 2 & 2 \\
\hline & 2006 & 7 & 4 & 0 & 2 & 2 & 0 & 1 \\
\hline \multirow{5}{*}{$\begin{array}{c}\text { Injury } \\
\text { [Crashes/year] }\end{array}$} & 2002 & 22 & 53 & 13 & 30 & 5 & 11 & 11 \\
\hline & 2003 & 20 & 51 & 6 & 31 & 5 & 17 & 11 \\
\hline & 2004 & 29 & 47 & 7 & 38 & 10 & 25 & 17 \\
\hline & 2005 & 23 & 50 & 11 & 43 & 13 & 23 & 13 \\
\hline & 2006 & 23 & 32 & 6 & 29 & 4 & 12 & 20 \\
\hline \multirow{5}{*}{$\begin{array}{c}\text { PDO } \\
\text { [Crashes/year] }\end{array}$} & 2002 & 55 & 78 & 16 & 65 & 13 & 10 & 4 \\
\hline & 2003 & 47 & 94 & 12 & 63 & 12 & 5 & 8 \\
\hline & 2004 & 74 & 86 & 17 & 72 & 25 & 10 & 7 \\
\hline & 2005 & 83 & 94 & 20 & 92 & 31 & 10 & 11 \\
\hline & 2006 & 71 & 92 & 20 & 75 & 23 & 3 & 11 \\
\hline
\end{tabular}

In practice, the crash types potentially affected by traffic control and safety hardware conditions are head-on, sideswipe, fixed object, and run-off-road. The general statistics of historical data indicate 5 percent, 17 percent, 1 percent and 77 percent of crashes for the aforementioned crash types, respectively. The SI values are computed using the proposed method for individual highway segments.

\subsection{Validation of SI values}

First, the RMSE and GEH values are calculated for the consistency checks between the SI or EB crash estimates in reference to the observed crash frequencies for all highway segments. The computed RMSE values are 4.05 and 4.11 for SI and EB, respectively. These values reveal that the computed SI crash frequency values are marginally more accurate than EB crash frequency estimates, because of a slightly lower RMSE value. Further, the GEH value allows for consistency check between the SI or EB estimate and observed crash frequency for each highway segment independently. Of all 193 segments, the GEH values corresponding to individual highway segments calculated using either SI or EB estimates are lower than 5.0 for all segments, indicating that both the proposed and EB method yield acceptable crash frequency estimates.

Next, consistency checks between the SI or EB estimates and field observed crashes are performed using Chi-square, Spear's rank correlation, and Mann-Whitney $U$ tests mentioned in the previous section. The Chi-square statistics is calculated as 79.88 and lower than $\chi_{20.05 ; 192}$, indicating that there is no statistically significant difference between SI and EB crash frequency estimates. For estimating the Spearman's rank correlation coefficient, the SI values and EB crash estimates for individual highway segments are established and then paired to rank in ascending or descending orders. It provides a measure of association between the rankings of segment safety by SI and EB crash estimates. The Spearman's rank correlation coefficient, $p_{s}$, is computed as 13.58 and z-statistic at 95 percent confidence level is 0.98 , indicating that the ranking from the SI estimates and EB estimates do agree with each other at a high confidence level. Next, the Mann-Whitney $U$ test is conducted with an assumption that they are from the same population. The standard normal z-statistic, $|z|$, is computed as 
Z. Li et al.: Incorporating Traffic Control and Safety Hardware Performance Functions into Risk-based Highway Safety Analysis

2.09 and lower than $z_{0.05 ; 192}$, indicating that there is no statistically significant difference between SI and EB crash frequency estimates.

Finally, linear regression models are calibrated using SI and EB estimates for the 193 highway segments as illustrated in Figure 2, 3 and 4. The $R^{2}$ values showed the significance of correlations between the two sets of crash estimates, which are $0.93,0.85$, and 0.93 for fatal, injury, and PDO crashes, respectively. These exhibit relatively good fits between the SI values computed using the proposed risk-based method and EB estimates.
Table 5 - Summary of validation tests

\begin{tabular}{||l|c||}
\hline \multicolumn{1}{|c|}{ Statistical Tests } & Analysis Results \\
\hline \hline $\begin{array}{l}\text { Root-Mean-Square-Error } \\
\text { (RMSE) Test }\end{array}$ & $R M S E_{S I}=4.05$ \\
\cline { 2 - 3 } & $R M S E_{E B}=4.11$ \\
\hline Chi-Square Test & $\chi^{2}=79.88<\chi_{0.05 ; 192}^{2}$ \\
\hline Spear's Rank Correlation Test & $p_{s}=13.58<z_{0.95}$ \\
\hline Mann-Whitney U Test & $|z|=2.09<z_{0.05 ; 192}$ \\
\hline
\end{tabular}

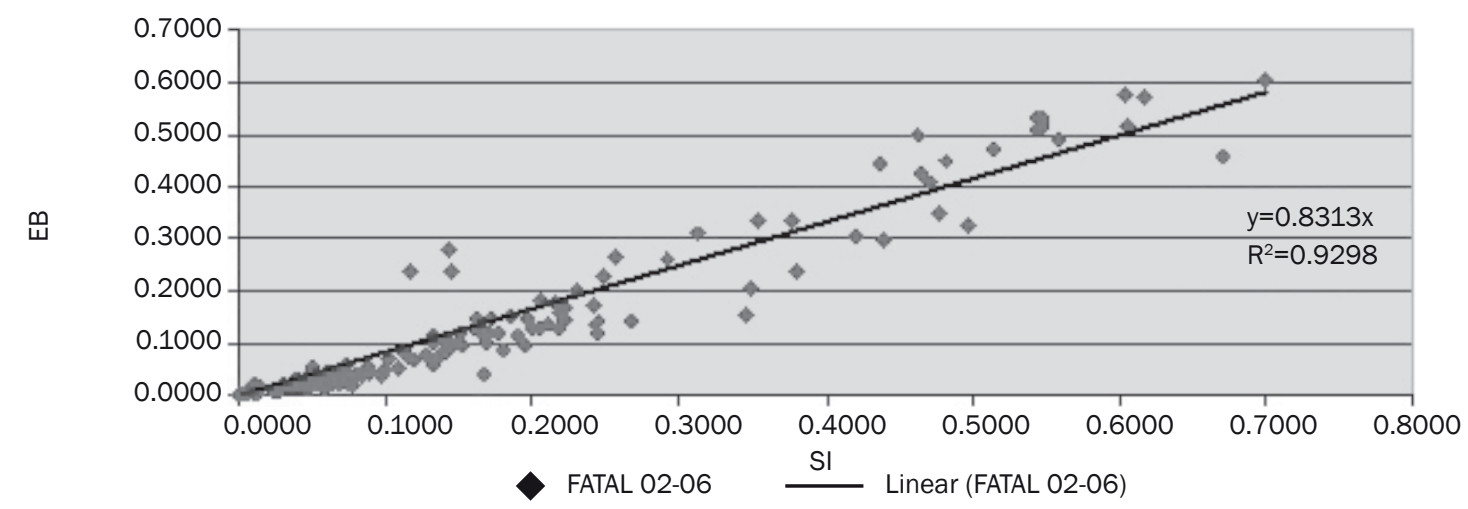

Figure 2 - Regression analysis of computed SI values and EB estimates for Fatal Crashes

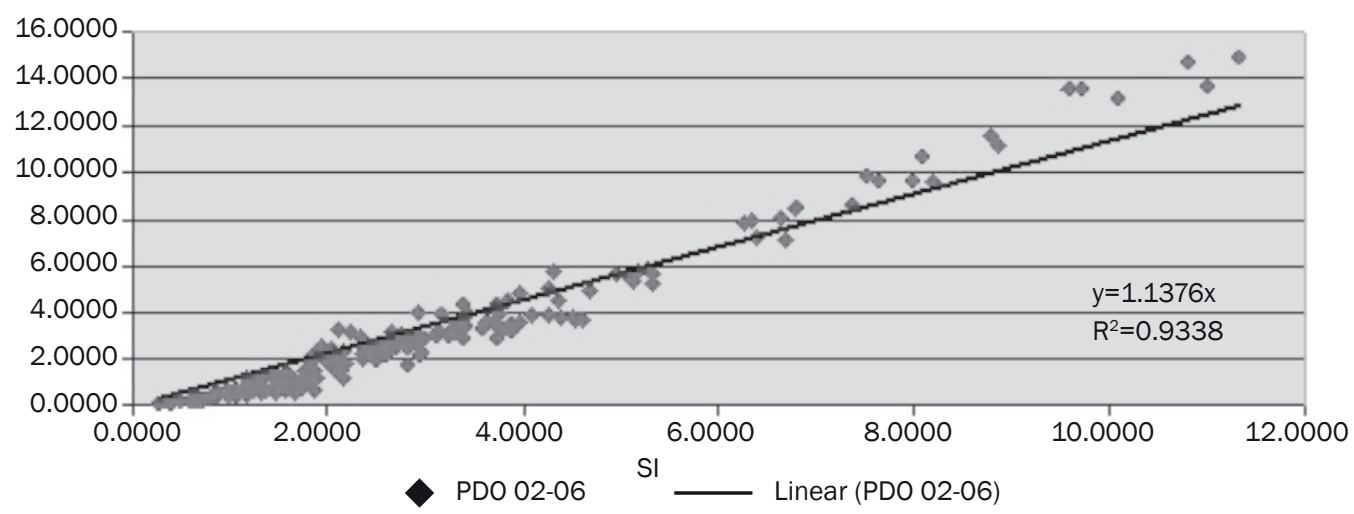

Figure 3 - Regression analysis of computed SI values and EB estimates for Injury Crashes

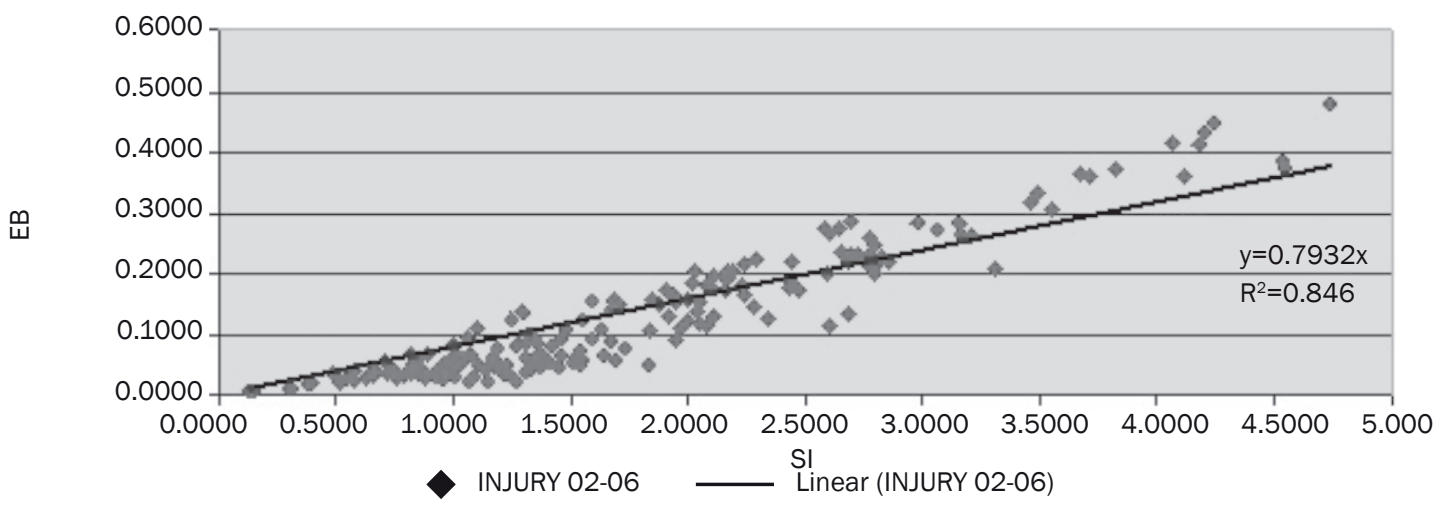

Figure 4 - Regression analysis of computed SI values and EB estimates for PDO Crashes 


\section{CONCLUSION}

Each year there are fatalities on the highway system attributable partly to inadequacies in the performance of traffic control and safety hardware, as its conditions deteriorate over time and effective analysis and management will dictate safety of highway users. This study has proposed refining of the exiting methods for highway safety analysis and management, as specifically utilizing the time-varying safety hardware performance functions to compute the Safety Index (SI) which correlates the traffic control and safety hardware condition. In particular, it introduces the combination of two refinements: i) introducing a disaggregated risk-based method for computing the safety index where it considers the performance functions for traffic control and safety hardware to compute the percentage changes in the crash frequency and severity as a function of hardware condition deterioration over time, and ii) incorporating a holistic system that combines data details of vehicle crashes and crash contributing factors concerning geometric design, traffic exposure, roadside features, and traffic control and safety hardware from various sources and provides a weighing scheme for factors collectively affecting crash occurrences.

The SI values calculated in the computational experiment are validated by using crash records and EB adjusted crash estimates via RMSE and GEH procedures, as well as Chi-square, Spearman's rank correlation, and Mann-Whitney U tests. The SI values and EB estimates exhibit a high level of consistency, but with a slightly low level of errors compared with the crash records. This suggests that the disaggregated risk-based method incorporating performance functions for traffic control and safety hardware is well suited for assessing safety impacts of condition changes in traffic control and safety hardware, such as signs and pavement markings.

In the broader context, the proposed method is applicable for evaluating the effectiveness of highway safety improvement projects. It is however cautioned that the data intensive nature of the method limits its usage to large-scale highway agencies that have the means and capability to maintain sufficient historical data on highway facility preservation, traffic operations, and crash records, as well as required data processing and analysis capabilities.

\section{李宗志 博士 (通讯作者)}

土建环境工程系, 伊利诺伊理工大学, 芝加哥市, 伊利诺伊州, 美国

电子邮箱: 1izz@iit. edu

HOANG DA0, 博士

土建环境工程系, 伊利诺伊理工大学, 芝加哥市, 伊利诺伊州, 美国

电子邮箱: hdao@hawk. iit.edu
HARSHINGAR PATEL，博士

土建环境工程系, 伊利诺伊理工大学, 芝加哥市,

伊利诺伊州, 美国

电子邮箱: hpate193@hawk.iit.edu

刘奕，博士

航运学院, 武汉理工大学, 武汉市, 湖北, 中国

电子邮箱: 1iuy87@hotmail.com

周备, 博士

公路学院, 长安大学, 西安市, 陕西, 中国

电子邮箱：bzhou2007@gmail.com

\section{将交通控制和安全设施特征方程} 纳入公路安全风险分析

李宗志

博士, 现为美国伊利诺理工大学土建环境工程系 终生教授。从长安大学 (原西安公路学院) 获工学 学士学位, 美国普渡大学分获交通运输与基础设施 系统工程硕士和博士学位, 期间还获得工业工程（ 运筹学专业）硕士双学位。专长为综合交通基础设 施和动态交通的机动性、安全性、安保、疏散归还 和应急管理、能耗和车辆尾气排放等管理目标的建 模; 可持续发展交通资产管理- 依托大数据对综合 交通系统多个绩效式管理目标, 交通基础设施和动 态交通流之间的关联性、整合性、及风险和不确定 性进行分析、信息挖掘、优化决策; 交通运输网经 济学。

关键词

交通控制，安全设施，交通安全特征方程，交通 安全，风险分析

\section{REFERENCES}

[1] Migletz J, Fish JK, Graham JL. Roadway Delineation Practices Handbook. Report FHWA-SA-93-001. Washington, D.C.: Federal Highway Administration; 1994.

[2] Ogden K. Safer Roads: A Guide to Road Safety Engineering. Cambridge: Avebury Technical; 1996.

[3] IMIT. Guidelines for the Design of Road Infrastructures: D.M. n. $6792,5 / 11 / 2001$. Rome: Italian Ministry of Infrastructures and Transports; 2001.

[4] Elvik R, Truls V. The Handbook of Road Safety Measures. Oxford: Elsevire Science; 2004.

[5] Lamm R, Beck A, Ruscher T, Mailaender T, Cafiso S, La Cava G, Mathews W. How to Make Two Lane Rural Roads Safer. Scientific Background and Guide for Practical Application. Southampton: WIT Press; 2006.

[6] Madanu S, Li Z, Abbas M. Life-Cycle Cost Analysis of Highway Intersection Safety Hardware Improvements. ASCE J Transportation Engineering. 2010 Feb;136(2):129-140.

[7] De Leur P, Sayed T. Development of a Road Safety Risk Index. TRB J Transportation Research Record. 2002 Jan;1784:33-42.

[8] Montella A. Safety Reviews of Existing Roads: Quantitative Safety Assessment Methodology. TRB J Transportation Research Record. 2005 Jan;1922:62-72. 
[9] Cafiso S, La Cava G, Montella A, Pappalardo G. A Procedure to Improve Safety Inspections Effectiveness and Reliability on Rural Two Lane Highways. Baltic J Road and Bridge Engineering. 2006 Mar;|(3):143-150.

[10] Black KL, McGee HW, Hussain SF, Rennilson JJ. Service Life of Retroreflective Traffic Signs. FWA-RD-90-101. Washington, D.C.: Federal Highway Administration; 1991.

[11] Wolshon B. Louisiana Traffic Sign Inventory and Management System, Final Report. Baton Rouge: Louisiana State University; 2003.

[12] Long S, Qin R, Gosavi A, Wu CH, Ryan T, Noll C. Life Expectancy Evaluation and Replacement Schedule Development for LED Traffic Indicators. Report No. OR11.015. Jefferson City: Missouri Department of Transportation; 2011.

[13] Lindly JK, Yellapu K, Supriyasilp T. Evaluation of Retroreflectometers for the Alabama Department of Transportation. Report 02402. Tuscaloosa: University of Alabama; 2002.

[14] Bahar G, Masliah M, Erwin T, Tan E, Hauer E. Pavement Marking Materials and Markers: Real-World Relationship between Retroreflectivity and Safety over Time. Final Report for NCHRP Project 17-28. Washington, D.C.: National Cooperative Highway Research Program, National Research Council; 2006.
[15] Avelar,R,Carlson,P.Linkbetween PavementMarkingRetroreflectivity and Night Crashes on Michigan Two-Lane Highways. TRB J Transportation Research Record. 2014 Dec;2404:59-67.

[16] Guo, Y, Liu, P, Liang, Q, Wang, W. Effects of Parallelogram-Shaped Pavement Markings on Vehicle Speed and Safety of Pedestrian Crosswalks on Urban Roads in China. Elsevier J Accident Analysis \& Prevention. 2015 Oct;95(B):438-447.

[17] Klir GJ. Uncertainty and Information: Foundations of Generalized Information Theory. Hoboken: Wiley Interscience; 2006.

[18] Hauer E. Observational Before-After Studies in Road Safety: Estimating the Effect of Highway and Traffic Engineering Measures on Road Safety. Oxford: Pergamon Press; 1997.

[19] Ross, Jr, HE, Sicking DL, Zimmer RA, Michie JD. Recommended Procedures for the Safety Performance Evaluation of Highway Features. NCHRP Report 350. Washington, D.C.: National Cooperative Highway Research Program, National Research Council; 2005.

[20] McCullagh P, Nelder JA. Generalized Linear Models. New York: Chapman and Hall; 1989.

[21] Kutner M, Nachtsheim C, Neter J, Li W. Applied Linear Statistical Models. 5th Ed. New York: McGraw-Hill/ Irwin; 2004. 